\title{
Assess the Impact of Urban Expansion on the Periphery Residence in Debre Tabor Town in Case of Kebele 01
}

\author{
Fekadie Bazie Enyew \\ Department of Geography and Environmental Studies, Kabridahar University, Korahey zone, Somali Regional State, Ethiopia.
}

How to cite this paper: Fekadie Bazie Enyew. (2021) Assess the Impact of Urban Expansion on the Periphery Residence in Debre Tabor Town in Case of Kebele 01. Journal of Humanities, Arts and Social Science, 5(1), 143-156.

DOI: 10.26855/jhass.2021.01.015

Received: March 30, 2021

Accepted: April 27, 2021

Published: May 31, 2021

*Corresponding author: Fekadie Bazie Enyew, Department of Geography and Environmental Studies, College of Social Science and Humanities, Kebri Dahar University, Ethiopia.

Email: fekadiebazie03@gmail.com

\begin{abstract}
Urban expansion is the common phenomena in both developing and developed countries. The study focus on the impact of urban expansion on the periphery residence in Debre Tabor town in case of Kebele 01. The study was incorporated about the effects of urban expansion on the livelihood of the surrounding community, its effect on the natural environment and their causes. To achieve this objective, the data was collected from primary and secondary data source and used a mixed type of research method. The researcher was used both probability and non-probability sampling techniques. The sample was selected from 8,889 total households, from this the researcher select 99 respondents by using simple random probability sampling technique and thus sample size determined by using systematic probability sampling technique in Kth rule, then select every 90th interval. The data were collected by using different data collection tools like questionnaire, interview and field observation, and secondary data gathered from published and unpublished materials. Finally, the data were analyzed in different ways like graphs, tables through SPSS and GIS software. The findings also indicate that the horizontal expansion of urban area has impacts on the periphery residence such as impacts on the environment, social and economic aspects, and thus impact affect the livelihoods of the people especially agrarian community, because agricultural land is changing in to urban areas effect on health and affect other socio economic conditions of the community. Therefore at the end of this study, some recommendations are forwarded that can improve the livelihood of the society by giving fair and effective compensation for their land.
\end{abstract}

\section{Keywords}

SPSS, Periphery, Urban, Community, GIS

\section{Introduction}

Urbanization is the common phenomenon in both developing and developed countries. The united nation projected that half of the world population would live in urban areas at the end of 2008 (UN, 2008). Displacement due to urban expansion is widespread in the developing countries than the developed countries (Martine G. et al., 2017), because the majority of the people in developing countries live highly concentrated in the periphery depending on agriculture with fragmented land holding. In many ways, urban expansion is a spontaneous phenomenon that leads to displacing rural farming community (Tegegne, 1999).

In Africa context, the dramatic effects of rapid urbanization are very clear in activities of urban areas. As cities 
expand the main zone, direct impact is the peri-urban areas and whose living in Peri Urban interface, the challenges and opportunities in meeting needs and the products of Urban population. However, there are some challenges as food shortage, poor infrastructure and lack of housing are the problems faced by governments as during such rapid urbanization (Rees, 1997). Approximately 25 percent of Africa's population lived in towns and cities in 1975 . In 2000, 38\% of the continent population lived in urban areas and the proportion is expected to increase to $47 \%$ by 2015 and to double by 2050 (Thou, 2010).

Ethiopia is characterized by low level of urbanization even by African standard, where only $15 \%$ of population lives in urban areas. Despite this, it has recorded a relatively high growth rate of Urban population (3.8\% annually), double that of rural areas, however, such high growth rate is not often accompanied by the development in socio-economic services and infrastructures and economic and employment capacity of the urban centers to support the growing population (Teller \& Asefa, 2010).

Following out ward urban expansion, peri-urban land use pattern would change from the one dominated by agriculture to a multiple land scape. The problem of rapid and uncontrolled urban growth and its consequence is on regional land scape in developing countries (Adeboyejoe et al., 2007).

Rapid population increase urbanization and changing socio-economic pattern are deriving forces that influenced special change in Peri Urban areas (Jongkroy, 2009). Urbanization and urban growth are considered as a modern way of life manifesting economic growth and development, however, urbanization and urban development in Ethiopia faced a number of socio-economic problem (Tegegne, 2002).

Debre Tabor town is one of the towns in Amhara region. In this regard, the study was incorporated in the town with the impact of urbanization on the periphery residence. In the area, urbanization is growing fast and the periphery residence incorporates in urban area (Keble 01 Administrative office, 2009).

As many international urban expansion experiences have been proven, in the process of urban development and growth, it can be the peripheral communities that are highly affected (Shine, 2015). During the process, such urban expansion affects more of the farmers in Peri Urban territory, especially in developing countries and more of the agrarian economy countries like Ethiopia (Berhe, 2006).

Debre Tabor town, especially Kebele 01 has experienced in physical expansion of urban areas. In this regard, Stokes's (1962) has stated that excessive alteration of the land use has been taking place without formal procedures and this has led to imbalance of land uses, squatter settlement, environmental degradation, inadequate infrastructure, poor sanitation, inadequate waste disposal treatment and shortage of other social infrastructure.

At the periphery of Debre Tabor town, especially Keble 01 agricultural lands has been used for Urban settlement due to continues expansion on the surrounding area and this expansion leads to the farmers lose their land, decrease agricultural productivity and crime due to mismatch between the land value and their compensation give to the farmers (Keble 01 Administrative office, 2009).

The severity of the problem in the study area motivates the investigator to conduct research on impacts of Urban expansion on the periphery residence and urbanization has the major phenomena that community faces many problems and its uncontrolled issue, however, many research have been conduct on this title, but the problem is still severe and unsolved issue, hence there was no research conducted in the study area on this title before, hence it is believed that there is a gap to explain and clarify the effects of urban expansion on the periphery communities on the existed research, so this study is therefore hoped or willing to fill this gap.

\section{Material and Methods}

\subsection{Description of the study area}

\subsubsection{Geographical location}

Debre Tabor town is the center of south Gondar administrative zone which is located in north central Ethiopia in Amhara regional state. It is found near Guna Mountain which is the second highest point in Amhara region as well as in Ethiopia next to Ras Dashen in north Gondar which is 4,620 m. It is located $666 \mathrm{~km}$ far from Addis Ababa, the capital city of Ethiopia and $50 \mathrm{~km}$ east of lake tana and its absolute location lies at $11^{\circ} 50^{\prime} 40^{\prime \prime}$ to $11^{\circ} 52^{\prime} \mathrm{N}$ (latitude) and $38^{\circ} 0^{\prime} 40^{\prime \prime}$ to $38^{\circ} 2^{\prime} \mathrm{E}$ (longitude) with the elevation of 2,706 masl (Ethiopia mapping agency, 2009).

\subsubsection{Topography}

Topographically, the town characterized by undulating terrain with significant latitudinal variation. It has the highest and the lowest elevation. The highest elevation of the town is 2,884 masl and the lowest elevation of the town 
is 2,440 masl. The town is characterized by hill and undulation land form with topography of $66 \%$ undulation, $20 \%$ plain, 14\% of rock land surface (Debre Tabor town profile, 2009).

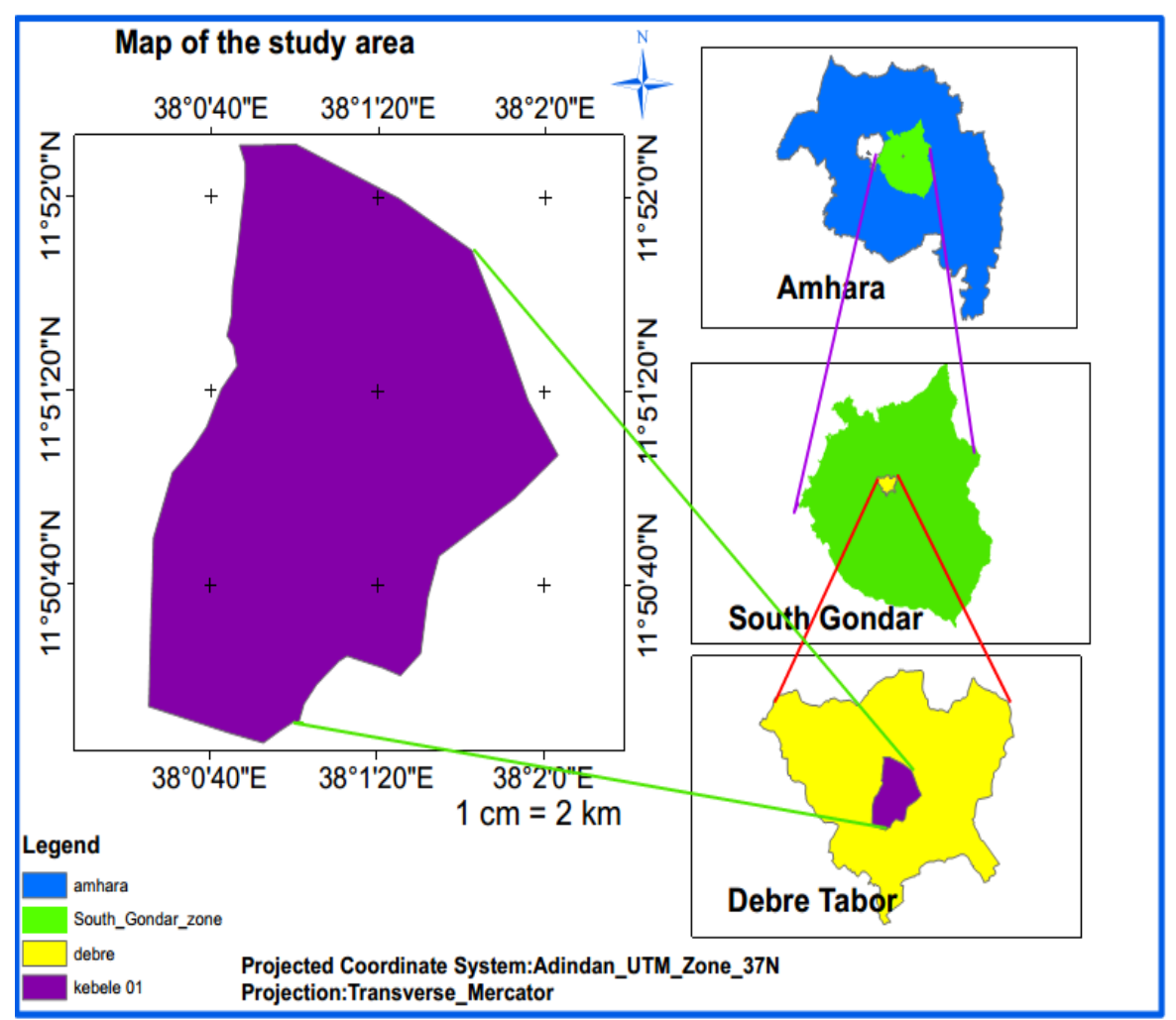

Map of the study area.

\subsubsection{Climate}

Debre Tabor town is located in the tropical climate type which receives seasonal rainfall and characterized by Woina dega climate zone with the mean annual rainfall of 1,553.3 $\mathrm{mm}$ per year and the mean daily temperature is $15^{\circ} \mathrm{C}$ (Meteorology Agency, 2007).

\subsubsection{Population}

Based on 2007 national census conducted by central statistics agency of Ethiopia, the total population of the town was 55,596 from which 27,644 were males and 27,956 were females. In 2008, the total population of Debre Tabor town were 83,082 from this 39,781 were males and 43,301 were females. In 2009, the total population of the town is 92,530 from this 44,305 were males and 48,225 were females and the total population of Kebele 01 is 29,339, from which 14,763 are males and 14,576 are females.

\subsubsection{Socio-economic activity}

The economic activity of the town is dominated by commercial activity (trading) followed by manufacturing enterprise. The urban-rural interaction of the town and its surrounding have contribute to business activity, but the town divided in to urban and rural Keble's, the rural society engaged in primarily economic activity, i.e., mixed agriculture such as production and animal rearing. The main social structure of the town mainly Amhara (98.93\%), other ethnic groups made up of the population. The majority of the inhabitants follow Ethiopian Orthodox Christianity with $96.6 \%$, while $1 \%$ are Muslim community and the remaining are other part of ethnic group of the population (Debre Tabor town profile, 2009).

\subsection{Methodology}

\subsubsection{Research Design}

To conducte this study, the researcher used a mixed type of research method, i.e., both the quantitative and qualitative research method, and the study was assessed urban expansion and its impact on the periphery residence in Debre Tabor town in case of Keble 01. 


\subsubsection{Sample technique}

The researcher used both sample techniques, i.e., probability and non-probability sampling technique. From the probability sampling technique, the investigators used simple random and systematic technique and from non-probability sampling purposive sampling technique may use. The reason why used simple random probability sampling technique is to minimize the bias and in order to give equal chance for every community who live in the study area, and use systematic sampling select the respondent in $\mathrm{K}^{\text {th }}$ interval and select the study area by using purposive sampling technique.

\subsubsection{Sample size}

In the study area Keble 01, according to the recent data, there were about 29,339 total populations. From these 8,889 are households, from the total house hold determining 99 respondents were select as a sample by using (Yamen formula, 1967), and by using systematic sampling technique to select 99 respondents in every $\mathrm{K}^{\text {th }}$ interval used.

Yamen (1967) formula of sample size determination=N/1+N (e)2,

Where $\mathrm{n}=$ Sample size

$\mathrm{N}=$ Total house hold

$\mathrm{e}=$ Level of precision $(10 \%)$

So, $\mathrm{n}=8889 / 1+8889(10 \%) 2$

$=8889 / 1+8889(0.1) 2$

$=8889 / 1+8889(0.01)$

$=8889 / 1+88.89$

$=8889 / 89.89$

$=98.88 \sim 99$

Finally, the researcher was selected as a sample by using systematic sampling technique, i.e., Kth rule used to determining the sampling interval.

i.e. $\mathrm{K}=\mathrm{N} / \mathrm{n}$, Where $\mathrm{N}=$ Total house hold

$\mathrm{n}=$ Sample size

So, $\mathrm{K}=8889 / 99$

$=89.7 \sim 90$ th, this means the first sample was selected randomly and then every 90th interval was selected i.e., the first sample draw randomly from the sample frame is 3, then it continuous as 3, 93, 183, 273, 363... until we select 99 respondents.

\subsubsection{Data source}

The researcher used both primary and secondary data sources to gathering relevant data for the study. Among the primary data source include observation, interview, and questionnaire and also the researcher refers data from published and unpublished materials.

\subsubsection{Data collection technique}

(1) Primary data collection technique

Questionnaire

The data for this study were collected through questionnaire to collect quantitative and qualitative data. The researcher used both open ended and close ended types of questionnaire to answer by choosing an option from a number of a given alternative and specifying their own views. The researcher distributes 99 questionnaires about the impacts of urban expansion on the periphery residence in Keble 01. The questionnaire primarily prepared in English and translates into Amharic language for the sack of simplicity.

Interview

The interview was conducted for the head of municipality and head of land administration office, as well as some local people and house hold head in study area. The researcher interviewed 4 peoples from head of municipality and 5 peoples from land administration office, as well as 10 people's interview from some local people and house hold head in the study area. The interview was concerned about the impact of urban expansion on the periphery residence and on the social service provision.

Field observation

Firsthand information on the field was collected by the direct observation on the selected area for this study. The researcher observed and collected the necessary visual information by using camera and others instruments was used.

(2) Secondary data collection techniques 
Secondary data were gathered from the published and unpublished materials like maps, reports and internet service to supplement primary data sources and use office documents for requiring data about population numbers, socio-economic backgrounds and others.

\subsubsection{Methods of data analysis}

To analyze the data collected from primary and secondary data sources, the researcher used both qualitative and quantitative analysis techniques. The qualitative technique were used to analyze and express in the form of statement, words and symbols, like their perception of the community, while the quantitative technique used to analyze and express in numerical values and present in terms of frequency and by using percentage, graphs, tables and charts etc and analyze the collected data by using SPSS software.

\section{Data Analysis and Interpretation}

Urban expansion is the common phenomena that affect in both developing and developed countries (Yang, 2016). The researcher has tried to collect data to identity the impact, factors and effects of urban expansion on the periphery residence in Debre Tabor town in case of Keble 01.

\subsection{Socio-economic background of the respondents}

Before discussing major objectives of the study, it is quite necessary to explain the characteristics of respondents. Based on the data collected from respondents in different data collection tools like field observation, interview and questionnaire, therefore their responses analyzed as follows.

\subsubsection{Sex composition of the respondents}

In this findings, the incorporates of sex composition is necessary to show the more vulnerable group (male and female) in case of urban expansion and their problems that facing by the residents based on office report in Kebele 01, there is a high proportion of male households than female house hold.

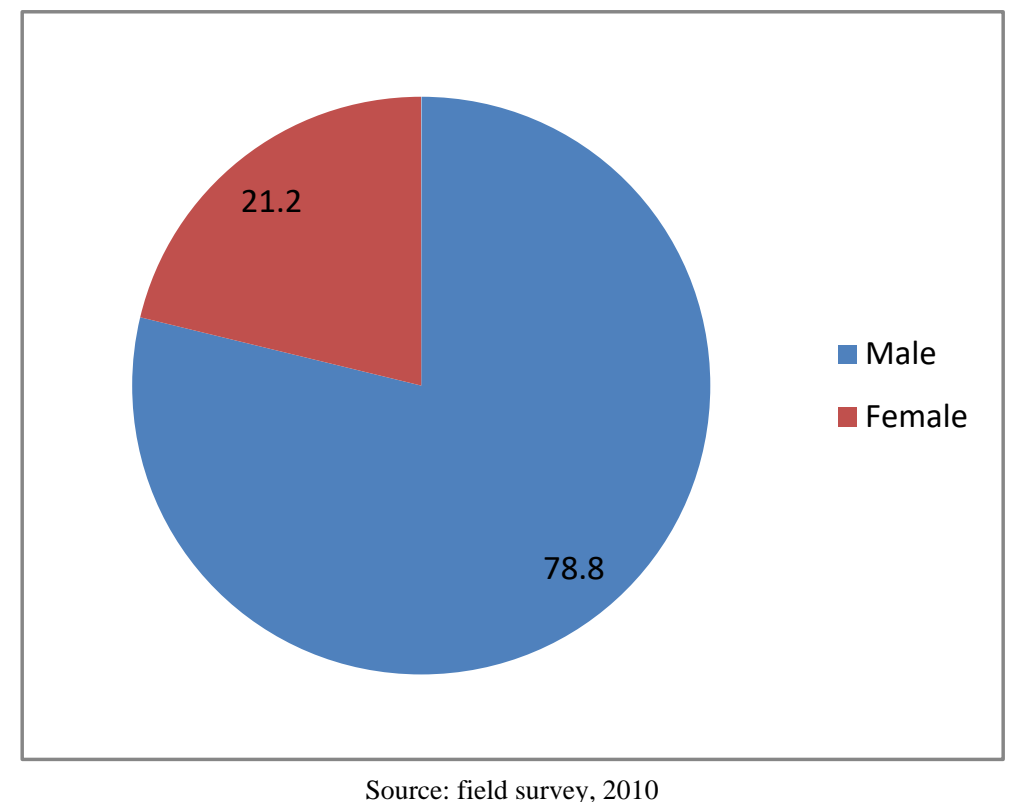

Figure 1. Sex composition of the respondents.

In this study, 99 respondents were selected as a sample and from which 78 were males and 21 were females and they share the percentage of $78.8 \%$ and $21.2 \%$ respectively. This shows the highest proportion of respondents were males, because based on the data collected from interview implies that in the periphery area farmers lose their land in case of urban expansion, therefore male farmers are more responsible than females.

\subsubsection{Age distribution of the respondents}

In 2014, the United Nation (UN) set out provisional guidelines on standard international age classification. Based on this, the researcher categorized them into four groups. Age distribution plays a great role in this finding. 
Table 1. Age distribution of the respondents

\begin{tabular}{cccc}
\hline Age & Frequency & Percent (\%) \\
\hline$<24$ & 7 & 3.1 & 36.4 \\
$25-44$ & 36 & 35.3 & 21.2 \\
$45-64$ & 35 & 21 & 100 \\
& $>64$ & 99 & \\
\hline
\end{tabular}

Source: Filed survey, 2010.

Based on the data shown in Table 1, the age of the respondents have been classified in UN age classification standards i.e. age $<24,25-44,45-64$ and $>64$, which consists of $7.1 \%$, 36.4\%, 35.3\% and $21.2 \%$ respectively. The majority (36.4\%) of the respondents age lies on the category of age 25-44. The age distribution is related to our findings because to know the most displaced and vulnerable age group due to urban expansion. Based on the data collected from key informants age group $(>64)$ is relatively vulnerable group than the other because they are old, due to this unable to participate in different economic activity, and in the study area as well as in a country level lack of old age security, therefore affected by Urban expansion related problems.

\subsubsection{Educational level of the respondents}

During field observation shows that educational level have factors to affect residents. Most of the time the expansion of urban areas influence the illiterate ones, because most surrounding farmers were unable to read and write and they engage in primarily economic activity.

Table 2. Educational level of the respondents

\begin{tabular}{ccc}
\hline Educational level & Frequency & Percent (\%) \\
\hline Illiterate & 33 & 33.3 \\
Grade 1-8 & 27 & 27.3 \\
Grade 9-12 & 22 & 22.2 \\
Diploma & 11 & 11.1 \\
Degree and above & 6 & 6.1 \\
Total & 99 & 100 \\
\hline
\end{tabular}

Source: field survey, 2010.

According to the field survey report, the highest proportion of the respondents were illiterate which accounts $33.3 \%$,they canot read and write and that is why they primarily engaged in agriculture rather than other sectors. Similarly in Teketel (2015), the findings show that most of the periphery residence farmers were engaged in primarily economic activity by this case, they could not read and write, and the remaining 27.3\%, 22.2\%, $11.1 \%$ and $6.1 \%$ were grade 1-8, grade 9-12, diploma and degree and above respectively.

\subsubsection{Occupational status of the respondents}

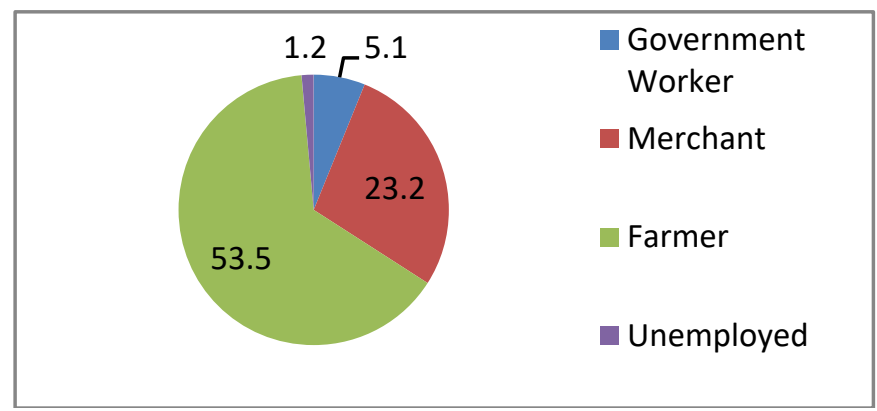

Source: Field survey, 2010

Figure 2. Occupational status of the respondents. 
Figure 2 shows that the majority of the respondents were farmers which account $53.5 \%$ from the total respondents. According to the data collected from interview mostly farmers were vulnerable to the effects with regarding to urban expansion and they lost their farm land. Study conducted by Mintesnot (2006), emphasized that farmers are the most susceptible for several problems by the cause of urbanization like lost their farm land this leads to decrease their income, migration and others. The remaining $23.2 \%, 18.2 \%$, and $5.1 \%$ were merchant, unemployed and government worker respectively.

\subsubsection{Martial status of the respondents}

Table 3. Marital status of the respondents

\begin{tabular}{ccc}
\hline Marital status & Frequency & Percent (\%) \\
\hline Married & 76 & 76.8 \\
Unmarried & 20 & 20.2 \\
Divorced & 3 & 3 \\
Windowed & - & - \\
Total & 99 & 100 \\
\hline
\end{tabular}

Source: Field survey, 2010.

In Table 3, married respondents were the highest in proportion from the total respondents, which is $76.8 \%$, because, according to the field survey report (age distribution) most of the respondents age is $25-44$, so they were married and family households, their livelihoods depending on primary economic activity, due to this mostly affected by urban expansions and facing to several socio-economic constraints.

\subsection{Causes of urban expansion in Keble 01}

Many people's investigate about the causes of urban expansion, for instance, according to Todaro (2000), emphasized that the main reason for the growing of urban areas are due to natural increase and migration as a whole. From his point of view in the study area, the principal cause of urbanization is analyzed as follows.

Table 4. Cause of urban expansion in Keble 01

\begin{tabular}{|c|c|c|c|}
\hline Item & Option & Frequency & Percent (\%) \\
\hline \multirow{3}{*}{$\begin{array}{c}\text { Do you believe that urban } \\
\text { expansion is increasing in } \\
\text { Keble } 01 ?\end{array}$} & Yes & 99 & 100 \\
\hline & No & - & - \\
\hline & Total & 99 & 100 \\
\hline
\end{tabular}

Source: Field survey, 2010.

Table 4 indicates that most (100\%) of the respondents suggested that there is an increasing of urban expansion in Keble 01 as compared to previous status. Based on the data collected from interview, due to the increasing of urban areas in Keble 01 many agricultural lands changed in to urban settlement and farmers lost their land, due to this decrease productivity, income and vulnerable to other related problems. And in addition to Farber (2006), suggests that worldwide urban system is expanding in to lands that are vulnerable for agricultural and forest production and impinge on the health and resilience of socio ecological system. These land use changes produce current benefits at the cost of eliminating future options for ecosystem goods and services.

According to Cohen (2005), when a given country urban growth is highly increasing as they expected more than their plan of rate we call it high, and the rate is moderately increasing the rate is medium, and finally the growth rate of urban area is less than the expected plan of a given country or their goal it is low growth rate. So based on the above, clarification and data collected from interview and field observation evaluate as a medium growth rate of urban expansion in Kebele 01 as compared to the last 10 years. And most (64.6\%) of the respondents replied as a medium growth rate from the total respondents. The remaining $27.5 \%$ and $8.1 \%$ were responses high and low growth rate respectively. 


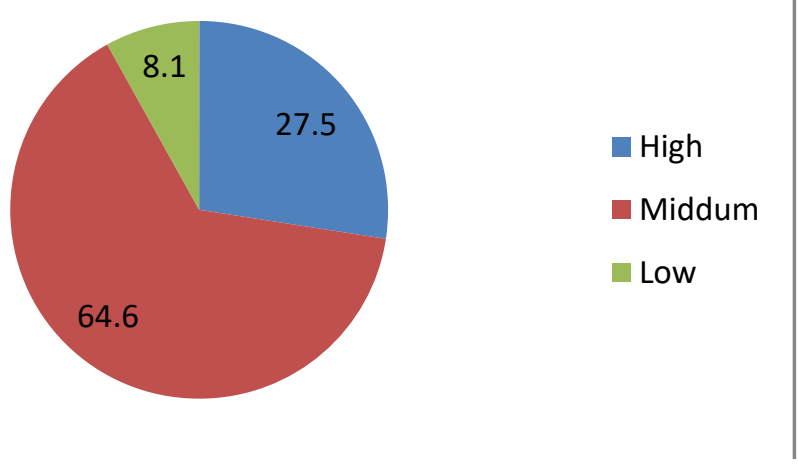

Source: field survey, 2010

Figure 3. The rate of urban growth in Kebele 01.

Table 5. Loss of farm land due to urban expansion

\begin{tabular}{cccc}
\hline Items & Option & Frequency & Percent (\%) \\
\hline & Yes & 81 & 81.8 \\
Did you lost your farm land by & No & 18 & 18.2 \\
the cause of urban expansion? & Total & 99 & 100 \\
\hline
\end{tabular}

Source: field survey, 2010.

Table 5 shows that most (81.8\%) of the respondents were lost their agricultural land due to the expansion of urban areas. And the remaining (18.2\%) of them responses that there is no lost of agricultural lands due to urban expansion. Similarly based on the data collected from interview, and field observation most farmers displaced and lost their land in case of urban expansion.

\subsubsection{Dominant factors of urban expansion in Kebele 01}

In the study area, there are several causes with related to urban expansion among thus are migration, natural increase, economic growth and development and others.

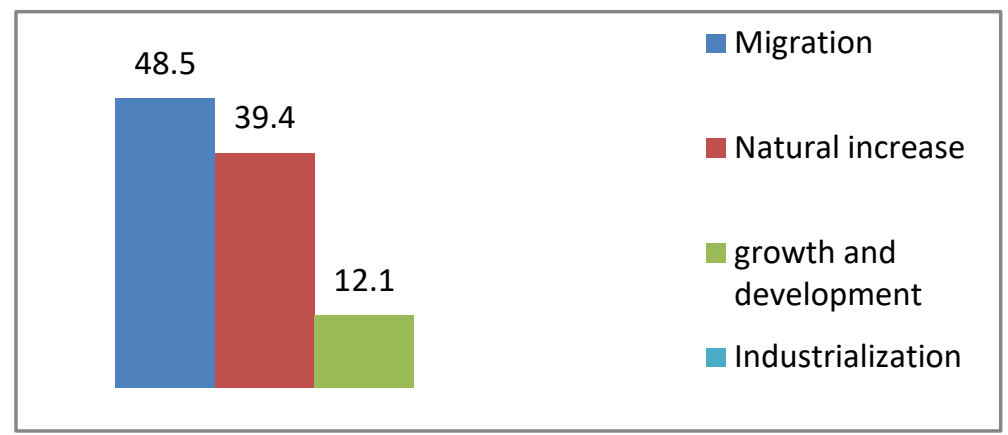

Source: field survey, 2010

Figure 4. Major factors of urban expansion in Kebele 01.

Figure 4 shows that the majority (48.5\%) of the respondents were responses that the dominant cause for the expansion of urban areas in Kebele 01 is rural to urban migration. The remaining were includes natural increase, economic growth and development and other, which accounts $39.4 \%$, and $12.1 \%$ from the total respondents respectively. Similarly, the data collected from interview and field observation implies that thus factors play a great role and contribute for the expansion of urban areas in the study area. But other findings emphasize that in the past time, natural increases is the major cause for the expansion of urban areas due to several factors like inadequate health facility, absence of family planning and other factors. In this study currently due to the invention of medicines and health facilities the birth rate becomes decrease, so the dominant factor is rural to urban migration. 
Table 6. Solutions for urban expansion

\begin{tabular}{|c|c|c|c|}
\hline Causes & Solutions & Frequency & Percent (\%) \\
\hline \multirow{5}{*}{ Rural-urban migration } & Expansion of rural area infrastructure & 24 & 27.6 \\
\hline & Strength a strong leader ship & 1 & 1.1 \\
\hline & Create job opportunity & 20 & 23 \\
\hline & Create awareness for rural society & 6 & 7 \\
\hline & Total & 51 & 58.7 \\
\hline \multirow{4}{*}{ Natural increase } & Expansion of health facility & 9 & 10.3 \\
\hline & Educate for family planning & 15 & 17.2 \\
\hline & Create awareness about contraceptive & 12 & 13.8 \\
\hline & Total & 36 & 41.3 \\
\hline
\end{tabular}

Source: Field survey, 2010.

As Table 6 shows that the dominant factor for urban expansion in Kebele 01 is rural urban migration and natural increase, which accounts $48.5 \%$ and $39.4 \%$ respectively, so based on this data collected from the respondents that the solution for this factors was analyzed in Table 12, which implies that the main solution for rural-urban migration is expansion of rural area infrastructure, create job opportunity mostly in rural areas, create awareness for rural society and strengthen a strong leadership, which consists $27.6 \%, 23 \%, 7 \%$ and $1.1 \%$ respectively. While the solution for natural increase educates about family planning, create awareness about contraceptive and expansion of health facility, which accounts $17.2 \%, 13.8 \%$, and $10.3 \%$ respectively. Based on the data collected from interview the main solution for thus causes is provision of different social infrastructure in both urban and rural areas.

\subsection{Effects of Urban expansion on the periphery residence}

Urban expansion affects the periphery residence in different ways. According to Teketel (2015) findings emphasize that urban expansion affects the livelihoods of the periphery residence, such as affects economically, socially and environmental influence on the surrounding community. Similarly in Kebele 01, urban expansion affects the periphery residence livelihoods.

Table 7. Effects of Urban expansion on the periphery residence

\begin{tabular}{cccc}
\hline Items & Option & Frequency & Percent (\%) \\
\hline \multirow{2}{*}{$\begin{array}{c}\text { Does urban expansion affect } \\
\text { your life? }\end{array}$} & Yes & 99 & 100 \\
& No & - & - \\
\hline
\end{tabular}

Source: Field survey, 2010.

Table 7 indicated that the most (100\%) of the respondents were suggested that their life is affected by urban expansion. Based on the data collected from interview show that most of the periphery residence directly or indirectly affected by urban expansion. Similarly, the existing findings show that urban expansions influence their life such as socially, economically, environmentally and psychologically affect the way of life.

Table 8. Response with regard to the effects of urban expansion on the periphery residence

\begin{tabular}{ccc}
\hline Effects of urban expansion & Frequency & Percent (\%) \\
\hline Loss of agricultural land & 24 & 24.3 \\
Displacement of farmers from their land & 52 & 52.5 \\
Loss of income & 10 & 10.1 \\
Unemployment & 13 & 13.1 \\
Total & 99 & 100 \\
\hline
\end{tabular}

Source: Field survey, 2010.

As Table 8 indicated that the effect of urban expansion are loss of agricultural land (24.3\%),displacement of farmers from their land (52.5\%), loss of income (10.1\%), and unemployment (13.1\%) from the total respondents. 
This shows most of the respondents displaced from their land and loss of their agricultural land which accounts (52.5\%) and (24.3\%) respectively. Similarly, the previous study emphasizes that urban expansion is adverse effect on the periphery residence particularly peoples engaged in primarily economic activity livelihoods. In addition to this effect, the interview data show that the farmers are vulnerable to other economic and environmental problems due to urban expansion.

Based on United State household income classification standard, we classified their income of respondents in the study area in 1,500 interval.

Table 9. Farmers' income before displaced from their land

\begin{tabular}{ccc}
\hline Monthly income (in birr) & Frequency & Percent (\%) \\
\hline $1,000-1,500$ & 1 & 10 \\
$1,600-2,500$ & 2 & 20 \\
$2,600-3,000$ & 2 & 50 \\
$>3,000$ & 5 & 100 \\
Total & 10 & 20 \\
\hline
\end{tabular}

Source: field survey, 2010.

As Table 9 indicates that the majority (50\%) of the respondents before displaced from their farm land have a monthly income above 3,000 birr. According to the data collected from interview implies that before their displacement, the farmers gain highest monthly income from agriculture livelihoods, while the other includes $20 \%, 20 \%$, and 10\% which means 2,600-3,000 birr, 1,600-2,500 birr and 1,000-1,500 birr respectively. In addition to this, the existing findings emphasize that before farmers displaced from their agricultural land, they have a better life to sustaining their livelihoods by producing surplus food production (Tegegne, 2002).

Table 10. Size of land before displacement

\begin{tabular}{ccc}
\hline Size of land (in ha) & Frequency & Percent (\%) \\
\hline $0.5-1.5$ & 21 & 21.2 \\
$2-3$ & 51 & 51.5 \\
$4-5$ & 23 & 23.2 \\
$>5$ & 4 & 4.1 \\
Total & 99 & 100 \\
\hline
\end{tabular}

Source: Field survey, 2010.

Table 10 shows that the highest proportion (51.5\%) of the respondents have owned 2-3 hectare of land before displaced their land due to urban expansion. Based on the data collected from interview and observation implies before farmers was displaced from their land they have been owned large size of land.

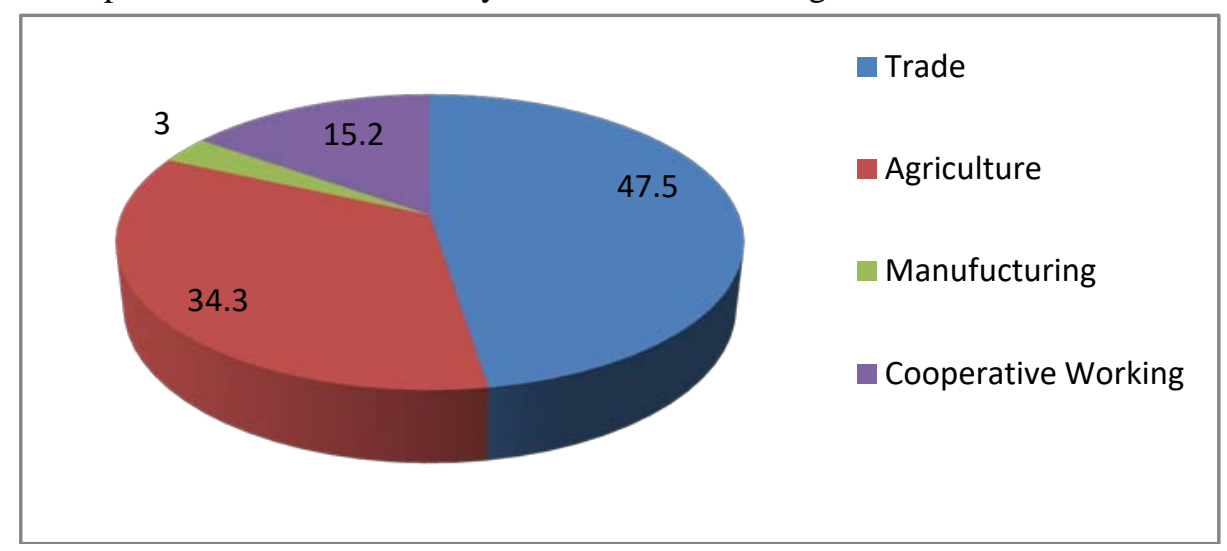

Source: Filed survey, 2010

Figure 5. After displacement from the livelihoods of their family. 
Figure 5 shows that the major livelihoods of the respondents after displaced from the previous status, the peoples were engaged in trade, agriculture, manufacturing and cooperative working, which consists $47.5 \%, 34.5 \%$, $3 \%$ and $15.2 \%$ respectively. Most (47.5\%) of the respondents were engaged in trade after displaced from original status due to urban expansion. The data collected from interview imply that governments compensate money for displaced persons, and then thus persons engaged in trade activity. Similarly the data review from other findings shows that after peoples displaced from their farm land, they were engaged in trade livelihoods by using compensated money from government.

Table 11. Amount of income of farmers after displaced from their land

\begin{tabular}{ccc}
\hline Monthly income (birr) & Frequency & Percent (\%) \\
\hline Below 1,000 & 52 & 52.5 \\
$1,000-1,500$ & 22 & 22.2 \\
$1,600-2,000$ & 17 & 17.2 \\
$>2,000$ & 8 & 8.1 \\
Total & 99 & 100 \\
\hline
\end{tabular}

Source: Field survey, 2010.

Table 11 implies that the most (52.5\%) of the respondents lost their monthly income after displaced from their agricultural land and their monthly income is below 1,000 birr due to the expansion of urban areas and the farmers were vulnerable to different problems which results reduction of their income and affect livelihoods.

Due to the causes of urban expansion many people's lost their farm land and displace from their economic activity, due to balance thus impact, the government provided a compensation to affected persons either in the form of in cash or in kind.

Table 12. Government compensation to displaced peoples

\begin{tabular}{cccc}
\hline Items & Option & Frequency & Percent (\%) \\
\hline & Yes & 88 & 88.9 \\
Does the government provide & No & 11 & 11.1 \\
compensation? & Total & 99 & 100 \\
\hline
\end{tabular}

Source: Field survey, 2010.

As we can see from Table 12, most (88.9\%) of the respondents replied that the most of the time the government provided a compensation for the displaced in return to their farm lands, while some $(11.1 \%)$ of the respondents responses that the government does not support or provide the farmers in giving the compensation and they were vulnerable to several factors. Based on the data collected from interview and field observation, most of the time the government provides a compensation for their displaced farmers either in cash or In kind. similarly Melese (2017) conducted on this, because government provide a compensation for thus residents who lost their farm land due to the expansion of the town, not only for the loss of agricultural land but also give compensation for their perennial trees.

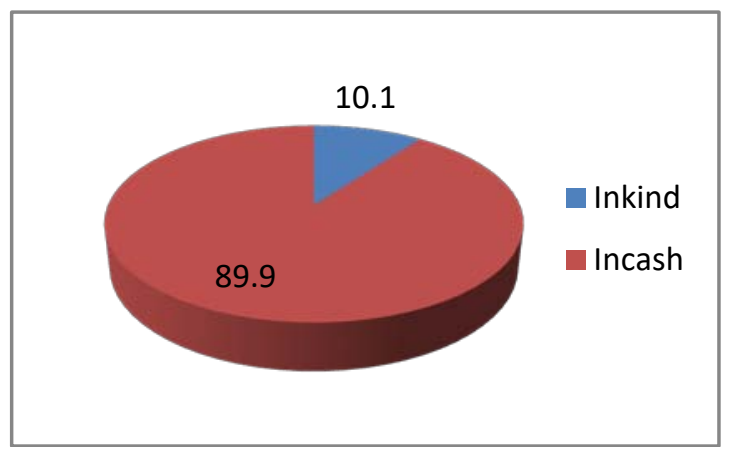

Source: Field survey, 2010

Figure 6. Compensation type gives to displaced peoples. 
Figure 6 shows that the government provide a compensation for displaced peoples in the form of in cash (89.9\%) from the total respondents. But the remaining (10.1\%) of the respondents also respond that the compensation has achieved by giving the equivalent land. Similarly other findings, interviews and observations shows that mostly the government provide a compensation in the form of cash, because in Kebele 01 there is inadequate lands to give compensation in the form of in kind to displaced peoples.

Before displaced from their agricultural land farmers sustained their livelihoods and peoples satisfy their family basic necessities' relatively the current livelihood activity.

Table 13. Compensate money or land as compared to previous livelihoods

\begin{tabular}{|c|c|c|c|}
\hline Items & Option & Frequency & Percent (\%) \\
\hline \multirow{3}{*}{$\begin{array}{l}\text { Did you think that compensated money or } \\
\text { land is sufficient as compared to your } \\
\text { previous livelihood? }\end{array}$} & Yes & 2 & 2 \\
\hline & No & 97 & 98 \\
\hline & Total & 99 & 100 \\
\hline
\end{tabular}

Source: Field survey, 2010.

Table 13 shows that the compensation provided to displaced peoples was insufficient as compared to previous livelihood, and in this finding most (98\%) of the respondents responses that the compensated money or land is insufficient as compared to previous livelihood, while the remaining (2\%), the compensated money or land is sufficient to sustain family basic necessities. Based on the data collected from interview and observation, it is obvious that capital shortage is common in all developing countries, so by this case the compensation value is insufficient as compared to the previous status. Because the respondents justify that there is lack or imbalance estimation or valuation of the earth's value and their compensated money or land i.e., money is easily lost and their in kind land is distanced and vulnerable to different economic problems and leads to land fragmentation, and high cost of living as compared to previous status.

\subsection{Impact of Urban expansion on the environment}

According to Seto (2018), it suggested that the conversion of the earth's land surface to urban uses is one of the most irreversible human impacts on the global biosphere. It hastens the loss of highly productive farm land, affects energy demand, alters the climate, modifies hydrologic and biogeochemical cycles, fragments of habitats and reduces biodiversity. In the study area, the expansion of urban areas affect the natural environment like solid waste disposal, change climate condition, pollution and others.

Table 14. Impact of Urban expansion on the environment

\begin{tabular}{cccc}
\hline Items & Options & Frequency & Percent (\%) \\
\hline $\begin{array}{c}\text { Do you think that urban ex- } \\
\text { pansion has impact on the }\end{array}$ & Yes & 99 & 100 \\
environment? & No & - & - \\
\hline
\end{tabular}

Source: field survey, 2010.

Based on the above response, we can understand that there are many problems on the environment which raised as a result of urbanization in the town, which accounts all (100\%) of the respondents suggested that urban expansion affects the natural environment, and similarly the interviewee replied that urban expansion directly or indirectly impact on the environment like exposed to pollution, disease, degradation of soil quality, waste related problems and others.

Based on the above data, we can understand there are many impacts on the environment results from urban expansion which includes solid waste disposal, pollution of water, deforestation and decrease soil quality, which consists about 44.4\%, 29.3\%, 16.2\% and 11.1\% from the total respondents respectively. Most (44.4\%) of the respondents agreed that solid waste disposal is the major Impact due to urbanization on the surrounding environment. 


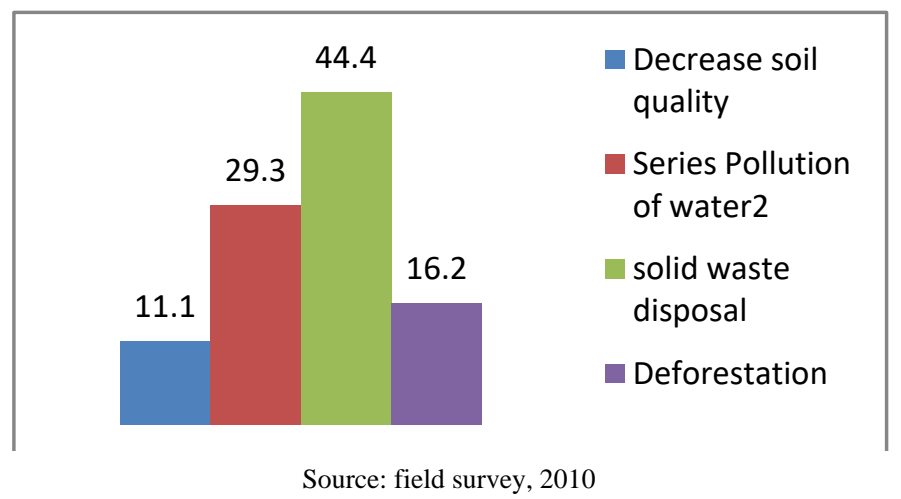

Figure 7. Impacts related to urban expansion.

\subsubsection{Environmental problems related to urban expansion}

According to UN (2004), urban populations interact with their environment. Urban people change their environment through their consumption of food, energy, water, and land. And in turn, the polluted urban environment affects the health and quality of life of the urban population. Based on the data collected from interview and field observation, the periphery residence facing by different environmental problems due to urbanization like loss of natural ecosystem, pollution, waste, noise pollution and others.

Table 15. Environmental problems related to urban expansion

\begin{tabular}{ccc}
\hline Environmental problem & Frequency & Percent (\%) \\
\hline Loss of natural ecosystem & 1 & 1 \\
Alter climate condition & 33 & 33.3 \\
Affect the quality and quantity of water & 51 & 51.5 \\
Disease & 14 & 14.2 \\
Total & 99 & 100 \\
\hline
\end{tabular}

Source: Field survey, 2010.

Table 15 shows mostly urban expansion affects the environment that facing the periphery residence which includes affect the quality and quantity of water, alter climate condition, disease, and loss of natural ecosystem which accounts $51.5 \%, 33.3 \%, 14.2 \%$ and $1 \%$ of the total respondents respectively.

\section{Conclusion}

Urbanization is a worldwide phenomenon in both developing and developed countries. There are a number of factors which contribute to the expansion of urban areas such as, rural urban migration, natural increase, economic growth and development, industrialization and others.

Urban expansion has impacts on the livelihood of the surrounding or urban periphery residence. The major impacts of this horizontal expansion are loss of agricultural land and displacement of the residence from their farm land, and it is an impact on the natural resources such as a uses for forest destruction, loss of habitat, decrease in quality and quantity of water, pollution, and solid waste disposal. Urban expansion has impacts on the socio economic activity such as crime, unemployment, congestion, housing problem and other related problem. Similarly, the finding also shows that the most of the periphery residence directly or indirectly affected by urban expansion in social, environmental and economic aspects.

\section{Recommendations}

Based on the finding of the study the following recommendations were forwarded.

The town administration should provide proper or equal compensation for the periphery residence that lose their land.

The government should find out alternative means of increasing agricultural production within limited land size.

To avoid imbalance, unhealthy and unsustainable growth of human settlement, the Kebele administration should promote land use patterns that minimize the present fast rate of land use change (conversion of agricultural land and of land use change conversion of agricultural land and forest in to urban settlement). This is because the life of pe- 
riphery farmer is very much affected by urban expansion that leads the farmers to loss their land.

Social service provision problem is one that is caused by urban expansion, therefore, the Kebele administration should make balance of the expansion of urban growth and the provision of social services for settled population.

Land is a basic resource, which has reached a stage of scarcity in a certain area today because of urban expansion, so in order to control thus problem, the Kebele administration should enact properties and regulations regarding conversion of agricultural land to urban use.

\section{References}

Adebojejo, A. (2007). Predictive modeling of urban expansion and implication for livelihood and sustenance in Peri Urban areas of Ogbmoso, Nigeria, a paper presented at African conference at Tanzania, Arusha.

Berhe G/Hiwot. (2006). Urban growth and its impact on land use, in case of Mekelle.

CSA of Ethiopia. (2007). Demographic and health survey; Addis Ababa, Ethiopia.

Debre Tabor town profile (2010).

Ethiopian mapping Agency (2009).

Hugo G. New forms of urbanization: Beyond the Urban-Rural Dichotomy. Routledge; Abingdon-on-Thames, UK: 2017.

Jiang, Li, Xiangzheng Deng, and Karen C., Seto. (2013). "The impact of urban expansion on agricultural land use intensity in China”, Land Use Policy, 35: pp. 33-39.

Jongkroy. (2009). Urbanization and changing settlement in Peri urban Bangkok, Kasetstart J.

Keble 01 administrative office. (2010).

Martin, G., Martial, A. (2017). State of world population: Unleashing the Potential of Urban Growth. UNFPA; New York, NY, USA: 2017.

Seto Karen C., Burak Guneralp, and Lucy R., Hutyra. (2018). "Global forecasts of urban expansion to 2030 and direct impacts on biodiversity and carbon pools", USA.

Shin, H. B. (2015). International Encyclopedia of the Social and Behavioral Science. $2^{\text {nd }}$ ed. Elsevier; Amsterdam, the Netherlands: 2015. Urbanization in china; pp.973-979

Tegegne G/Egizabher. (2002). Urban policy and strategy in Ethiopia proceeding of the second annual conference, Addis Ababa, association of Ethiopian geographer.

Teller and Assefa H/Mariam. (2010). The demographic transition and development in Africa; the unique case of Africa.

Thou, T. (2010). Community response to land use transformation in Nairobi, rural-urban fringe, Kenya, University of Waikato.

United Nation. (1980). Patterns of urban and rural population growth.

United Nation. (2008). World urbanization prospects; New York, the 2004 revision, united nation university press.

Yamen. (1967). Research methodology.

Yang, G., Ming, Q. (2016). Pressures of urbanization on ecology and environment in Inner Mongolia. Arid land geogr. 2016. 